\title{
Exhaled and nasal nitric oxide in chronic rhinosinusitis patients with nasal polyps in primary care*
}

\author{
Martin Frend $\varnothing^{1}$, Kåre Håkansson', Susanne Schwer², Andreas T. Ravn ${ }^{3}$, \\ Howraman Meteran 4 , Celeste Porsbjerg ${ }^{4}$, Vibeke Backer ${ }^{4}$, Christian von \\ Buchwald \\ ' Department of Otorhin
Copenhagen, Denmark \\ 2 Susanne Schwer ear, nose and throat clinic, Valby, Copenhagen, Denmark \\ ${ }^{3}$ Frederiksberg ear, nose and throat clinic, Frederiksberg, Copenhagen Denmark \\ ${ }^{4}$ Department of Respiratory Medicine L, Bispebjerg Hospital and University of Copenhagen, Copenhagen, Denmark
}

Rhinology 56: 59-64, 2018

https://doi.org/10.4193/Rhino17.111

*Received for publication:

May 26, 2017

Accepted: October 14, 2017

Background: Chronic rhinosinusitis with nasal polyps (CRSwNP) is a common inflammatory disorder associated with lower airway disease. However, only few studies of CRSwNP from outside secondary/tertiary care centres have been published.

We recently reported an asthma frequency of $44 \%$ and $65 \%$ in primary and secondary care patients respectively. Therefore, we hypothesise that inflammation of the lower airways could be present in all CRSwNP patients, even without asthma.

Here, we assessed the degree of lower and upper airway inflammation using exhaled and nasal nitric oxide (NO) in primary care CRSwNP patients with and without asthma.

Methods: Fifty-seven patients who met the EPOS criteria for CRSwNP were prospectively recruited from primary care ear, nose and throat clinics. Nasal endoscopy was performed by an ear, nose and throat specialist upon enrolment. Additionally, 30 healthy controls were enrolled. Expiratory and nasal NO measurements and thorough pulmonary evaluation were performed. Pulmonary disease was diagnosed by a respiratory physician.

Results: Fifty-nine percent of CRSwNP patients with asthma showed elevated expiratory NO; the same was seen in $29 \%$ of nonasthmatic CRSwNP patients. Compared with controls, a high level of exhaled NO was significantly more prevalent in CRSwNP irrespective of asthma-status. Nasal NO was significantly lower in patients with CRSwNP compared with controls.

Conclusion: Subclinical eosinophilic lower airway inflammation is common in CRSWNP in the primary sector, even in the absence of asthma.

Key words: nasal polyps, sinusitis, asthma, nitric oxide, primary health care

\section{Introduction}

Chronic rhinosinusitis with nasal polyps (CRSwNP) is a common chronic inflammatory disorder which frequently affects bo2th

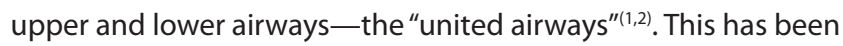
extensively documented, mainly in the secondary care (SC; hospital) sector in patients referred for endoscopic sinus surgery (ESS); however, the large group of patients managed in the primary care $(\mathrm{PC})$ sector have only been studied scarcely ${ }^{(3-6)}$. In the developed world, most patients with CRSwNP are managed in ear, nose and throat (ENT) clinics run by ENT specialists.
In Denmark, these ENT clinics offer free and direct access to management, including minor same day surgery, whereas ESS normally requires referral to $\mathrm{SC}$. We recently reported a previously unknown and very high prevalence of asthma (44\%) in PC patients suffering from CRSwNP, who had never been referred to the secondary or tertiary sector for $\mathrm{ESS}^{(7)}$.

Several factors have been suggested as pathophysiological link between the upper and lower airways. Yet, the background for united airways disease and the reason why only some develop asthma remains largely unknown ${ }^{(8-12)}$. Although different inflam- 
matory subtypes of CRSwNP are known, the variety associated with asthma and vastly predominant type in Caucasian patients is the eosinophilic type ${ }^{(13-15)}$. This has been shown extensively, including by our own group, which demonstrated an eosinophilic inflammatory pattern throughout the airway, including the bronchi ${ }^{(8,16)}$. In accordance with the united airways theory, it could be hypothesised that lower airway inflammation could be present even in non-asthmatic patients suffering from CRSwNP. Nitric oxide (NO) is found in the exhaled air and is elevated in case of lower airway inflammation present in eosinophilic asthma $^{(17)}$. Therefore, fractional exhaled NO (FeNO) levels are used in asthma monitoring to assess the degree of eosinophilic lower airway inflammation ${ }^{(18-21)}$.

Paradoxically, nasal NO ( $\mathrm{nNO}$ ) levels have been found to be lower in patients with CRSwNP compared with both nasally healthy patients and patients with chronic rhinosinusitis without nasal polyps, most likely due to compromised ostiomeatal patency $^{(22-24)}$.

Here, we aimed to evaluate eosinophilic airway inflammation using FeNO and nNO measurements in a PC CRSwNP population with and without asthma. We hypothesized that lower airway inflammation could exist in all CRSwNP patients, irrespective of asthma status. Additionally, we aimed to investigate nNO levels in relation to upper and lower airway disease.

We enrolled a previously undescribed patient group i.e. patients with CRSwNP in the PC sector, who had never been referred for surgery or had ESS performed.

To our knowledge, this is the first study to use standardised clinical evaluation and NO measurements to assess the association between upper and lower airway inflammation in patients with CRSWNP in PC never referred for ESS.

\section{Materials and methods}

\section{Design}

Patients were prospectively enrolled from nine PC ENT clinics in Copenhagen. Additionally, healthy controls from the general population were included via Internet advertisement. Inclusion criteria for the CRSwNP group were: age of 18-80 years and CRSwNP in accordance with the European Position Paper on Chronic Rhinosinusitis and Nasal Polyps (EPOS) criteria(1). Exclusion criteria were: previous or planned ESS, immunodeficiency, cystic fibrosis or primary ciliary dyskinesia, the need for linguistic interpreter, systemic steroid treatment within the preceding three months, upper respiratory tract infection within the preceding two weeks, non-white descent, pregnancy, or nursing. For the control group, inclusion criteria were 15-65 years of age, no history of respiratory disease, such as asthma and COPD, or hay fever and no atopy (defined as a positive skin prick test to 10 standard allergens). Exclusion criteria, other than the above mentioned, were similar to those of the CRSwNP group. The study was conducted in accordance with the Declaration of
Helsinki and was approved by the Ethics Committee of Copenhagen Capital Region (H-2-2013-015 and H-3-2011-121).

\section{Diagnosis and evaluation of nasal disease (CRSwNP) In accordance with the EPOS criteria, CRSwNP was defined as the presence of both objective findings and at least two specific symptoms of CRSwNP(1). In patients with CRSwNP, endoscopy was performed by an ENT specialist upon enrolment, while nasal symptom severity was assessed by the patient using a visual analogue scale ranging from zero to 10 , in which a higher score equals worse symptoms.}

\section{Diagnosis of asthma and allergy}

Lung function tests included spirometry, reversibility to $\beta 2$ agonist, mannitol challenge test and daily peak flow measurements (morning/night) for 14 consecutive days. Asthma was diagnosed by a respiratory physician in accordance with the Global Initiative for Asthma guidelines as the presence of respiratory symptoms and at least one positive asthma test ${ }^{(19)}$. Allergy was diagnosed using a skin prick test with a panel of 10 allergens according to international recommendations ${ }^{(25)}$. Further details about the pulmonary and allergy evaluation can be found in our previous paper ${ }^{(7)}$.

\section{Nitric oxide measurements}

Fractional exhaled NO (FeNO) and nNO was measured using a hand-held electrochemical device (NIOX MINO; Aerocrine AB, Solna, Sweden) in accordance with the manufacturers instructions and international guidelines ${ }^{(26,27)}$.

For nasal measurements, an adapter was used (NIOX MINO Nasal Test Kit; Aerocrine AB, Solna, Sweden) with a five $\mathrm{ml} / \mathrm{s}$ flow rate. Elevated FeNO was defined as FeNO $\geq 25 \mathrm{ppb}$ in accordance with the American Thoracic Society guidelines ${ }^{(28)}$.

\section{Statistics}

The statistical package IBM SPSS Version 22 (IBM, Chicago, IL, USA) was used. For categorical variables, we used the Pearson $\mathrm{X} 2$ test or the Fisher exact test, depending on the minimum cell counts in contingency tables. We used the Student's t-test for normally distributed data, the Mann Whitney U test for nonparametric data, and Shapiro-Wilk test and histograms to assess normal distribution of data. Pearson's or Spearman's tests were used to assess correlation between variables. Data were missing on pack-years $(n=3)$, FeNO $(n=1)$ and $n N O(n=6)$. A p value of $\mathrm{p}<0.05$ was considered statistically significant. Depending on the distribution of data, we elected to describe data by using internationally recognised cutoff-values ${ }^{(28)}$.

\section{Results}

Fifty-seven patients with CRSwNP and 30 healthy controls were enrolled. 
Table 1. Group characteristics and nitric oxide, CRSwNP patients and healthty controls".

\begin{tabular}{|c|c|c|c|}
\hline & $\begin{array}{l}\text { CRSwNP patients } \\
\qquad(n=57)\end{array}$ & $\begin{array}{l}\text { Healthy controls } \\
\qquad(n=30)\end{array}$ & P Value \\
\hline Sex (male, \%) & 70.2 & 36.7 & 0.52 \\
\hline $\begin{array}{l}\text { Age (yr), mean } \\
\text { (min-max) }\end{array}$ & $49.3(23-72)$ & $34.5(18-60)$ & $<0.01$ \\
\hline $\begin{array}{l}\text { BMI, median } \\
\text { (min-max) }\end{array}$ & $25.0(19-24)$ & $23.8(18-34)$ & 0.18 \\
\hline $\begin{array}{l}\text { FeNO (ppb), me- } \\
\text { dian (min-max) }\end{array}$ & $21.5(8-104)$ & $16.5(8-24)$ & $<0.01$ \\
\hline $\begin{array}{l}\text { nNO (ppb), me- } \\
\text { dian (min-max) }\end{array}$ & 168 (14-713) & $267(4-1141)$ & $<0.01$ \\
\hline
\end{tabular}

CRSwNP = chronic rhinosinusitis with nasal polyps; $\min =$ minimum; $\max =$ maximum; $\mathrm{BMI}=$ body mass index $; \mathrm{FeNO}=$ fractional exhaled nitric oxide; $\mathrm{nNO}=$ nasal nitric oxide.

\#Spirometric data on CRSwNP patients previously reported.

One participant in the control group had a unilateral nasal polypoid process in the middle meatus upon endoscopy, and did not meet the EPOS criteria for CRSwNP. None of the healthy controls had asthma, COPD or atopy, whereas $44 \%$ of patients with CRSwNP had asthma, 7\% had COPD and 32\% had atopy ${ }^{(7)}$. The healthy controls were, on average, 15 years younger than the patients with CRSwNP (Table 1) ${ }^{(29,30)}$.

\section{Fractional exhaled and nasal NO}

Median FeNO was 21.5 in patients with CRSwNP and 16.5 in healthy controls ( $p<0.01$; Table 1$)$. Also, FeNO was significantly higher in patients with asthma compared with non-asthmatic patients with CRSwNP ( $p=0.01$; Table 2). No significant difference was found in FeNO between respiratory healthy patients with
CRSwNP and the healthy controls (median 16.5 vs. 15.5 ppb; $\mathrm{p}=$ 0.3 ; Table 2). The prevalence of elevated FeNO (defined as feNO $\geq 25 \mathrm{ppb}$ ) was $44 \%$ in patients with CRSwNP and significantly higher in CRSwNP patients with asthma compared with respiratory healthy patients with CRSwNP (59\% vs. $29 \% ; p=0.02$; Table 2). Furthermore, elevated FeNO was significantly more prevalent in respiratory healthy CRSwNP patients compared with healthy controls ( $29 \%$ vs. $0 \%$; $p<0.01$; Table 2 ).

Median nNO was 168 ppb in patients with CRSwNP and 267 ppb in healthy controls and thus significantly lower in patients with CRSwNP ( $p<0.01$; Table 1). However, no difference was found between CRSwNP patients with and without asthma (175 vs. 168 $\mathrm{ppb} ; \mathrm{p}=0.62 ;$ Table 2). Finally, nNO was neither correlated with symptom severity (i.e. VAS scores; $p=0.45$ ), nor with FeNO ( $p=$ $0.6)$.

\section{Lung function}

Percentage of expected forced expiratory volume during the first second (FEV1\%) was significantly lower in CRSwNP patients than in healthy controls ( $93 \%$ vs. $102 \%$; $<<0.01$ ). This was also the case when comparing only the respiratory healthy CRSwNP patients with healthy controls ( $96 \%$ vs. $102 \% ; p=0.04$; Table 2 ).

\section{Nasal symptom severity \\ Although median VAS scores were higher in asthmatic than non-asthmatic patients, there was no significant difference (5.4 vs. $4.3 ; p=0.17$ ). \\ However, the prevalence of severe nasal symptoms (defined as a VAS score above seven) was significantly correlated to asthma, and found in $32 \%$ of asthmatic compared with $8 \%$ of respiratory healthy patients with CRSwNP ( $p<0.05$; Table 2).}

\section{Discussion}

To our knowledge, this is the first study on airway NO in patients

Table 2. Nitric oxide, pulmonary function and nasal symptom severity, CRSwNP patients +/- asthma and healthy controls".

\begin{tabular}{|c|c|c|c|c|c|}
\hline & $\begin{array}{l}\text { CRSwNP + asthma } \\
(n=25) ; 1\end{array}$ & $\begin{array}{l}\text { CRSwNP - asthma } \\
(n=28) ; 2\end{array}$ & Controls $(n=30) ; 3$ & P Value, 1 vs. 2 & P Value, 2 vs. 3 \\
\hline FeNO (ppb), median (min-max) & $33(11-104)$ & $15.5(8-69)$ & $16.5(8-24)$ & $<0.01$ & $0.3^{*}$ \\
\hline $\mathrm{nNO}$ (ppb), median (min-max) & $175(14-519)$ & $168(52-713)$ & $267(4-1141)$ & 0.62 & $<0.01$ \\
\hline$\uparrow$ FeNO (\%) & 64.0 & 28.6 & 0 & 0.01 & $<0.01$ \\
\hline FEV $1 \%$ of predicted, mean & 92.0 & 96.2 & 103.9 & 0.36 & 0.04 \\
\hline$\uparrow$ VAS (\%) & 31.8 & 8.3 & - & $<0.05$ & - \\
\hline
\end{tabular}

CRSwNP = chronic rhinosinusitis with nasal polyps; FeNO = fractional exhaled nitric oxide; $\min =$ minimum; $\max =$ maximum; $\mathrm{nNO}=$ nasal nitric oxide; $\mathrm{nNO}=$ nasal nitric oxide; $\uparrow$ FeNO $=$ FeNO $\geq 25$ parts per billion; FEV1 = forced expiratory volume during the 1 st $\mathrm{s}$; $\uparrow$ VAS $=$ visual analogue scale score for nasal symptoms > 7. \#Four patients with chronic obstructive pulmonary disease not included in table. * Trending towards higher FeNO in respiratory healthy patients with CRSwNP (2). 
with CRSwNP treated in the PC sector. Approximately half of these patients had asthma, and FeNO was elevated in 59\% in the asthmatic patients, indicating that asthma is a very common co-morbidity in CRSWNP in PC, and FeNO is a sensitive marker of asthma in these patients.

Furthermore, 29\% of the patients with CRSwNP, who were not found to have pulmonary disease, had an elevated FeNO indicating that lower airway inflammation might be present. Potentially, these patients could be in the process of developing asthma. This is supported by the observation that lung function was significantly lower in this group compared with the healthy controls.

Patients with severe nasal symptoms were also more likely to have asthma. This suggests that the levels of inflammation in the upper and lower airways correlate, which is in accordance with previous findings, including our own ${ }^{(7)}$.

Finally, we report that $\mathrm{nNO}$ is significantly lower in patients with CRSwNP from the PC sector than in healthy controls. This is in line with previous findings from the tertiary sector, but has until now not been shown in patients from the PC sector ${ }^{(24,29,31,32)}$. The lower $\mathrm{nNO}$ in CRSwNP patients likely reflects that, irrespective of where the patients are treated, nasal polyps block the sinuses. The fact that $\mathrm{nNO}$ and feNO were not significantly correlated suggests that the NO-rich nasal air does not significantly affect the orally exhaled air when measuring feNO.

Few studies have described upper and lower airway NO in CRSwNP patients. A Japanese study from the SC sector on 33 patients with CRSwNP, who never had ESS performed, found that 22 (66\%) had a high FeNO (defined as FeNO > 25 ppb). Of these, eight (36\%) had no history of asthma ${ }^{(33)}$.

In a Korean study from a tertiary treatment centre comprising 30 non-asthmatic, non-atopic patients with CRSwNP and 32 healthy controls, a significantly higher FeNO was found in the CRSwNP group (mean FeNO $=29.8$ ppb) compared with healthy controls (mean FeNO $=20.5 ; \mathrm{p}<0.009)^{(34)}$.

The results of both studies correspond with our findings. However, in neither study the asthma diagnosis was based on objective evaluation. This is a problem as questionnaire or single-test diagnosis is not a reliable method ${ }^{(7,35)}$. Furthermore, both studies were conducted in Asia. The immunological characteristics of CRSwNP vary significantly between races, which could affect the interplay between upper and lower airway inflammation and results from one region may not apply to all ${ }^{(36,37)}$.

A French study conducted in the SC sector on $\mathrm{nNO}$ and FeNO in 32 CRSwNP patients with and 25 without bronchial hyperresponsiveness, did not find a significant difference in FeNO (median values: 37 vs. 38 ppb; p > 0.05) nor in nNO (median values: 130 vs. $150 \mathrm{ppb} p>0.05)^{(24)}$. We found a significantly higher FeNO in patients with asthma. However, we also did not find a difference in nNO between asthmatic and non-asthmatic patients $(p=0.6)$.

Our results are important for several reasons.

Firstly, the high prevalence of lower airway inflammation in PC patients could imply that coexisting eosinohilic upper and lower airway disease is the rule rather than the exception. We have previously shown that the eosinophilic inflammation is significantly more pronounced in the nasal polyps compared to the bronchi in CRSwNP patients and that the inflammatory profile is similar throughout the airway ${ }^{(8)}$. Together, our findings indicate that upper airway inflammation in CRSwNP somehow initiates an inflammatory response in the lower airways, which in some but not all cases, leads to asthma.

Further, our results show that eosinophilic united airways disease is not only found in the most severely affected patients with CRSwNP referred for ESS in the SC sector. Most studies concerning CRSwNP are conducted in hospitals, although many patients are managed outside hospitals, and results from one sector may not apply to patients in other sectors.

Finally, the fact that not only asthmatic but also non-asthmatic patients have a reduced lung function, highlights the need for an interdisciplinary approach to united airways disease: rhinologists and respiratory physicians should work together, both in diagnosis, treatment and research to attain a better understanding and improved treatment options ${ }^{(38)}$. At our departments of ENT and respiratory medicine, we have recently opened a joint outpatient clinic for patients with concomitant upper and lower airway disease.

As undiagnosed asthma is common in CRSWNP patients, and leads to a lower quality of life, a method of predicting asthma in CRSwNP could yield a better prognosis in united airways disase ${ }^{(7,39)}$. We hypothesise that an elevated FeNO in CRSwNP patients, as found in this study, could potentially be a suitable tool, in PC as well as secondary and tertiary care sectors to identify patients at risk of developing adult-onset asthma. However, a longitudinal study is needed to determine this.

Additionally, as nasal disease is common, and frequently undiagnosed in asthma, we hypothesise that nNO measurements could be used as a non-invasive marker of nasal disease, when endoscopy is not feasible ${ }^{(3,40,41)}$.

Our study was limited by several factors. First, the control group was different from the CRSwNP group in several parameters including age, and although several studies did not find these parameters to affect NO, the effect on airway NO is not fully understood ${ }^{(29,30)}$. Pulmonary function results (FEV1\%) were adjusted for this and for other variables, and cut-off points for FeNO based on background population data ${ }^{(42)}$. Additionally, the fact that patients with atopy were not included in the control group should be kept in mind when evaluating our results; as should 
the fact that season (i.e. possible exposure to allergen) was not taken into account in the atopic patients ${ }^{(43)}$. Furthermore, when comparing our results with other results from the PC sector, it is important to note that the diagnosis of CRSWNP in this study was based on endoscopy by an ENT specialist.

Moreover, objective severity scores of nasal disease severity might elucidate relevant correlations to NO or lower airway disease.

Finally, selection bias could be in play when enrolling patients and healthy controls.

Overall, this study adds to the current knowledge of the united airways by including a large, previously poorly described patient group, i.e. patients from PC who have never undergone ESS. Furthermore, gold standard evaluation of both upper and lower airways was used, in accordance with internationally acclaimed diagnostic criteria.

\section{Conclusion}

The present study suggests that subclinical lower airway inflammation evaluated by measuring airway NO, is common in patients with CRSwNP in the PC sector and highlights the need for an interdisciplinary approach to the united airways.

\section{Acknowledgements}

We thank PC ENT specialists Anders Schermacker, Anne-Louise Reventlow-Mourier, Bo Huniche, Jeanne Rungby, Jesper

Micheelsen, Leif Hahn, Samih Charabi, and Torben Boesen for patient referrals.

This study was funded by the non-profit foundations Danish Regional Collaboration of Specialists Foundation ("Fonden for Faglig Udvikling af Speciallægepraksis") and Lundbeck Foundation ("Lundbeckfonden"). In-kind support was given by Pharmaxis Ltd.

None of these entities were involved in the conception, execution, interpretation, or publication strategy of this study.

\section{Authorship contribution}

MF, KH, VB, AR, SS and CV: Designed the study, prepared and conducted the clinical examinations and wrote the manuscript. HM: Enrolled and clinically examined all healthy controls and critically revised the manuscript.

$\mathrm{CP}$ : Contributed to the study design and planning, data interpretation and critical manuscript revision.

\section{Conflict of interest}

There are no conflicts of interest pertaining to this manuscript.

\section{References}

1. Fokkens WJ, Lund VJ, Mullol J et al. European Position Paper on Rhinosinusitis and Nasal Polyps 2012. Rhinol Suppl. 2012;23

2. Philpott C, Erskine S, Hopkins C et al. A casecontrol study of medical, psychological and socio-economic factors influencing the severity of chronic rhinosinusitis. Rhinology. 2016 Jun;54(2):134-40.

3. Larsen $\mathrm{K}$. The clinical relationship of nasal polyps to asthma. Allergy Asthma Proc. 1996;17(5):243-9.

4. Pearlman AN, Chandra RK, Chang D, Conley DB, Tripathi-Peters A, Grammer LC, et al. Relationships between severity of chronic rhinosinusitis and nasal polyposis, asthma, and atopy. Am J Rhinol Allergy, 2009 MarApr;23(2):145-8

5. Jarvis D, Newson R, Lotvall J et al. Asthma in adults and its association with chronic rhinosinusitis: the GA2LEN survey in Europe. Allergy. 2012 Jan;67(1):91-8.

6. Ragab A, Clement P, Vincken W. Objective assessment of lower airway involvement in chronic rhinosinusitis. Am J Rhinol. 2004 Jan-Feb;18(1):15-21.

7. Frendø M, Håkansson K, Schwer S et al. Asthma in ear, nose, and throat primary care patients with chronic rhinosinusitis with nasal polyps. Am J Rhinol Allergy. 2016 May;30(3):67-71.

8. Håkansson K, Bachert C, Konge L et al. Airway Inflammation in Chronic Rhinosinusitis with Nasal Polyps and
Asthma: The United Airways Concept Further Supported. PLoS One. 2015 Jul $1 ; 10(7)$

9. Kariyawasam HH, Rotiroti G. Allergic rhinitis, chronic rhinosinusitis and asthma: unravelling a complex relationship. Curr Opin Otolaryngol Head Neck Surg. 2013 Feb;21(1):79-86

10. Hens G, Vanaudenaerde BM, Bullens DMA et. al. Sinonasal pathology in nonallergic asthma and COPD: "united airway disease" beyond the scope of allergy. Allergy. 2008 Mar;63(3):261-7.

11. Kim HY, Dhong H-J, Chung SK, Chung Y-J, Kim M-G. Clinical characteristics of chronic rhinosinusitis with asthma. Auris Nasus Larynx. 2006 Dec;33(4):403-8.

12. Togias A. Rhinitis and asthma: evidence for respiratory system integration. J Allergy Clin Immunol. 2003 Jun;111(6):1171-83

13. Li N, Peters AT. Chronic rhinosinusitis management beyond intranasal steroids and saline solution irrigations. Allergy asthma Pro. 2015;36(5):339-43.

14. Hulse KE, Stevens WW, Tan BK, Schleimer RP. Pathogenesis of nasal polyposis. Clin Exp Allergy. NIH Public Access; 2015 Feb;45(2):328-46.

15. Mahdavinia M, Suh LA, Carter RG et al. Increased noneosinophilic nasal polyps in chronic rhinosinusitis in US second-generation Asians suggest genetic regulation of eosinophilia. J Allergy Clin Immunol. 2015 Feb;135(2):576-9.

16. Håkansson K, Thomsen SF, Konge L,
Mortensen J, Backer V, von Buchwald C. A comparative and descriptive study of asthma in chronic rhinosinusitis with nasal polyps. Am J Rhinol Allergy. 2014 SepOct;28(5):383-7

17. Guo FH, Comhair $S$ a, Zheng $S$ et al. Molecular mechanisms of increased nitric oxide (NO) in asthma: evidence for transcriptional and post-translational regulation of NO synthesis. J Immunol. 2000;164(11):5970-80.

18. Barnes PJ, Dweik RA, Gelb AF et al. Exhaled Nitric Oxide in Pulmonary Diseases. Chest. 2010 Sep;138(3):682-92.

19. Bousquet J, Clark TJH, Hurd S et al. GINA guidelines on asthma and beyond. Allergy. 2007 Feb;62(2):102-12.

20. Porsbjerg C, Lund TK, Pedersen L, Backer $V$. Inflammatory subtypes in asthma are related to airway hyperresponsiveness to mannitol and exhaled NO. J Asthma. 2009 Aug 9:46(6):606-12.

21. Silkoff PE, McClean P, Spino M, Erlich L, Slutsky AS, Zamel N. Dose-response relationship and reproducibility of the fall in exhaled nitric oxide after inhaled beclomethasone dipropionate therapy in asthma patients. Chest. 2001 May;1 19(5):1322-8.

22. Lundberg JO. Nitric oxide and the paranasal sinuses. Anat Rec, 2008 Nov;291(11):1479_ 84.

23. Colantonio D, Brouillette L, Parikh A, Scadding GK. Paradoxical low nasal nitric oxide in nasal polyposis. Clin Exp Allergy. 
2002 May;32(5):698-701.

24. Delclaux C, Malinvaud D, Chevalier-Bidaud B, Callens E, Mahut B, Bonfils P. Nitric oxide evaluation in upper and lower respiratory tracts in nasal polyposis. Clin Exp Allergy. 2008 Jul;38(7):1140-7.

25. Bousquet J, Heinzerling L, Bachert $C$ et al. Practical guide to skin prick tests in allergy to aeroallergens. Allergy. 2012 Jan;67(1):1824

26. Alving K, Janson C, Nordvall L. Performance of a new hand-held device for exhaled nitric oxide measurement in adults and children. Respir Res. BioMed Central; 2006;7(1):67.

27. American Thoracic Society, European Respiratory Society. ATS/ERS recommendations for standardized procedures for the online and offline measurement of exhaled lower respiratory nitric oxide and nasal nitric oxide, 2005. Am J Respir Crit Care Med. 2005 Apr 15;171(8):912-30.

28. Dweik R, Boggs P, Erzurum S, Irvin C. An Official ATS Clinical Practice Guideline: Interpretation of Exhaled Nitric Oxide Levels (FENO) for. Am J Respir Crit Care Med. 2011;184(1):1-33.

29. Ragab SM, Lund VJ, Saleh HA, Scadding G. Nasal nitric oxide in objective evaluation of chronic rhinosinusitis therapy. Allergy. 2006 Jun;61 (6):717-24.

30. Guida G, Rolla G, Badiu I et al. Determinants of exhaled nitric oxide in chronic rhinosinusitis. Chest. 2010 Mar;137(3):658-64.

31. Lundberg JO. Nitric Oxide and the Paranasal Sinuses. Anat Rec Adv Integr Anat Evol Biol. 2008 Nov;291(11):1479-84.

32. Arnal JF, Flores P, Rami J et al. Nasal nitric oxide concentration in paranasal sinus inflammatory diseases. Eur Respir J. 1999 Feb;13(2):307-12.

33. Takeno S, Taruya T, Ueda T, Noda N, Hirakawa K. Increased exhaled nitric oxide and its oxidation metabolism in eosinophilic chronic rhinosinusitis. Auris Nasus Larynx. 2013;40(5):458-64.

34. Jeong JH, Yoo HS, Lee $\mathrm{SH}$, Kim KR, Yoon HJ, Kim SH. Nasal and exhaled nitric oxide in chronic rhinosinusitis with polyps. Am J Rhinol Allergy. 2014;28(1):e11-6.

35. Backer $V$, Sverrild A, Ulrik CS, Bødtger U, Seersholm N, Porsbjerg C. Diagnostic workup in patients with possible asthma referred to a university hospital. Eur Clin Respir J. 2015;2(0)

36. Wang $X$, Zhang N, Bo M et al. Diversity of TH cytokine profiles in patients with chronic rhinosinusitis: A multicenter study in Europe, Asia, and Oceania. J Allergy Clin Immunol. 2016;138(5):1344-53.

37. Tomassen P, Vandeplas G, Van Zele T et al. Inflammatory endotypes of chronic rhinosinusitis based on cluster analysis of biomarkers. J Allergy Clin Immunol. 2016;137(5):1449-1456e4

38. Rix I, Håkansson K, Larsen CG, Frendø M von Buchwald C. Management of chronic rhinosinusitis with nasal polyps and coexisting asthma: a systematic review. Am J Rhinol Allergy. 015 May-Jun;29(3):193-201

39. Katotomichelakis M, Simopoulos E, Zhang $\mathrm{N}$ et al. Olfactory dysfunction and asthma as risk factors for poor quality of life in upper airway diseases. Am J Rhinol Allergy. Jan;27(4):293-8.

40. Esteban CA, Klein RB, Kopel SJ et al. Underdiagnosed and Undertreated Allergic Rhinitis in Urban School-Aged Children with Asthma. Pediatr Allergy Immunol Pulmonol. 2014 Jun;28;27(2):75-81.

41. Egan M, Bunyavanich S. Allergic rhinitis: the "Ghost Diagnosis" in patients with asthma. Asthma Res Pract. Asthma Research and Practice; 2015;1(1):8.

42. Djupesland PG, Chatkin JM, Qian W, Haight JS. Nitric oxide in the nasal airway: a new dimension in otorhinolaryngology. Am J Otolaryngol. 2015 25];22(1):19-32.

43. Kharitonov SA, Rajakulasingam K, O'Connor B, Durham SR, Barnes PJ. Nasal nitric oxide is increased in patients with asthma and allergic rhinitis and may be modulated by nasal glucocorticoids. J Allergy Clin Immunol. 1997;99(1):58-64.

\section{Martin Frendø}

Department of Otorhinolaryngology

Head and Neck Surgery and Audio-

logy

Rigshospitalet University Hospital

Blegdamsvej 9

2100 Copenhagcen

Denmark

Tel: +4535452071

Fax: +45 35452629

E-mail: martin.frendoe-soerensen.01@regionh.dk 